Cómo citar este artículo en MLA: Longoni, Bruno Andrés. "Semblanza de Carlos Tomatis en la narrativa de Juan José Saer”. Escritos 27. 59 (2019): 256-273. doi: http://dx.doi.

org/10.18566/escr.v27n59.a03

Fecha de recepción: 03.04.2019

Fecha de aceptación: 21.05.2019

\title{
Semblanza de Carlos Tomatis en la narrativa de Juan José Saer
}

\author{
Biographical Sketch of Carlos Tomatis \\ in Juan Jose Saer's Fiction \\ Esboço de Carlos Tomatis na narrativa de Juan José Saer
}

Bruno Andrés Longoni ${ }^{1}$

\section{RESUMEN}

Desde su anónima irrupción en "Algo se aproxima” hasta su último avistamiento en La grande, Carlos Tomatis, personaje emblemático en la narrativa del argentino Juan José Saer, se erige como metáfora de la esterilidad posmoderna en la melancólica figura del escritor sin escritura. Sorna epigramática, desdén autosuficiente y fantasías punitivas configuran su carácter melancólico y pendular (fiebre y geometría). Nuestro trabajo busca correlacionar su imposibilidad de capitalizar la experiencia en forma de narración (el mutismo como base del duelo y la melancolía, según Freud) con la escritura saereana, signada por destellos epifánicos (shocks, diría Benjamin) y una pulsión balbuceante que acaba, puntuación obsesiva mediante, por disolver la sintaxis. Si bien Tomatis y su troupe reproducen el tono hostil de los

1 Magíster en Estudios avanzados de literatura española e hispanoamericana por la Universidad de Barcelona (2017). Licenciado en Letras por la Universidad de Buenos Aires (2007). Profesor en la Universidad Industrial de Santander (Colombia), miembro del Grupo de investigación "Glotta" destinado a la literatura hispanoamericana. Correo electrónico: brunoandreslongoni@yahoo.com.ar 
ensayos saereanos de los años 60 y 70 signados por el rechazo a la doxa literaria, en su prolífico discurrir Saer constituye la inversión especular de su héroe condenado al silencio.

Palabras clave: Juan José Saer, Carlos Tomatis, Walter Benjamin, Freud

\begin{abstract}
Since his first anonymous appearance in "Algo se aproxima" until his last sighting in La Grande, Carlos Tomatis -recurring character in Juan Jose Saer's fictionestablishes himself as a metaphor of postmodern sterility, which is embodied in the melancholic figure of the writer without writing. Epigrammatic sarcasm, selfsufficient contempt and punitive fantasies reflect his melancholic and pendular (fever and geometry) personality, without giving up his view of literature as an autonomous realm of pure form. Bearing this in mind, the purpose of the article is to correlate the impossibility of the character to capture experience within fiction with Saer's own writing, which is distinguished by epiphanic hints and a stuttering drive that, through an obsessive punctuation, ends up by breaking up syntaxis.
\end{abstract}

Key Words: Juan Jose Saer, Carlos Tomatis, Lo Imborrable, Scars, La Grande

\title{
RESUMO
}

Desde sua aparição anônima em Algo se aproxima até sua ultima apresentação em La grande, Carlos Tomatis personagem habitual na narrativa de Juan José Saer, aparece como metáfora da esterilidade pós-moderna através da figura melancólica do escritor sem escrita. Sorna epigramática, desprezo autossuficiente e fantasias punitivas configuram seu caráter melancólico e pendular (febre e geometria), sem desistir por isso de seu olhar da literatura como reino autônomo da forma pura. Nosso trabalho tenta correlacionar sua impossibilidade de capitalizar a experiência sob a forma da narração com a escrita de Saer, caraterizada por lampejos de epifania e uma pulsão balbuciante que termina por dissolver a sintaxe através da pontuação obsessiva.

Palavras chave: Juan José Saer, Carlos Tomatis, o indelével, cicatrizes, La grande. 


\section{Un coup de dés jamais n’abolira le hasard}

$\mathrm{E}$ n el universo de Juan José Saer, la escritura es un juego peligroso, implica siempre un riesgo: la vida se torna descarte dejando en el artista, como efecto colateral, las marcas de su mutilación. Esa tajante dicotomía romántica, arte versus vida, se encarna respectivamente en las figuras de Adelina y Susana Flores, las hermanas del cuento "Sombras sobre un vidrio esmerilado", cuyas cicatrices (a Adelina le han extraído el seno izquierdo, Susana renguea de una pierna) son remanentes de una carencia, de otra mitad que han resignado en el sacrificio asumido. Susana, la hermana mediocre, se queda con Leopoldo, el hombre deseado por ambas; Adelina, la poetisa reconocida, pierde al amor de su vida, aunque la vida que, por lo demás, opera siempre como materia prima de la poesía, jamás deje de invadir la forma pura de la poesía: Adelina compone un soneto a partir de la sombra de Leopoldo sobre el vidrio esmerilado del baño. Las vejatorias palabras de Tomatis, por completo ajenas a la tensa solemnidad de toda conferencia, introducen el dedo en la llaga, la vida en el arte:

La señorita Flores -dijo, riéndose y poniéndose como pensativo- ha dicho hermosas palabras sobre la condición de los seres humanos. Lástima que no sean verdaderas. Digo yo, la señorita Flores, ¿̨ha estado saliendo últimamente de su casa? [...] Usted debería fornicar más, Adelina, sabe, romper la camisa de fuerza del soneto -porque las formas heredadas son una especie de virginidad- y empezar con otra cosa. (Saer, Cuentos 217)

La relación causal que Tomatis establece entre dos verbos, en principio lejanos semánticamente ("escribir" y "fornicar"), nos da la pauta del cariz pulsional que Saer imprime en su literatura, y abre una tenue posibilidad de reconciliación de los opuestos "arte" y "vida", que, en última instancia, será utópica para una poetisa como Adelina que ha llevado su apuesta hasta el final. Sin sacrificio, no hay poesía posible.

La mutilación de Adelina Flores en "Sombras sobre un vidrio esmerilado" adquiere un sentido metafórico; y si la poetisa era motivo de burla para un joven Tomatis reacio a aceptar el sacrificio de la vida en su insolente incitación a "fornicar más", el desgarramiento de su propia mitad sacrificada le volverá amplificado como vaga reminiscencia nostálgica que interrumpe su duermevela a bordo de un bus de larga distancia. 
Luego se hablará de un hermano mayor fallecido a las pocas semanas de vida, y cuyo nombre (Alberto Carlos) es luego invertido por sus padres para su nuevo hijo (Carlos Alberto). ${ }^{2}$ En su origen, Tomatis guarda una herida: su nacimiento viene a subsanar el dolor paterno por el hermano ido. Al ser menor que su hermano fallecido, no tiene forma de recordarlo y, sin embargo, su evocación perturba el sueño pacífico y cubre de melancolía a Tomatis en las últimas páginas de La grande (2005), como si la transgresión de Tomatis diera la vuelta completa a toda la narrativa de Saer para recaer en el tácito reconocimiento de su fracaso en su novela póstuma: su resignada conformidad con la mutilación implícita en toda elección estética. Dicha paradoja (la belleza mutilada) se encarnará, en esa misma novela, en el personaje de Diana, la hermosa y joven esposa de Nula cuya mano es amputada al nacer:

Nunca antes Saer había trabajado de este modo fantasioso y mágico un estereotipo que tiene la forma del oxímoron: Diana, la mutilada perfecta. $\mathrm{O}$ para decirlo con pesimismo: toda perfección es imposible, en toda perfección hay, siempre, una falta, error o carencia. (Sarlo 99)

Ya sea por falta, error o carencia, el arte jamás es perfecto. Arrancada la máscara del sentido, solo queda el azar; no por nada, apunta Panesi, las cuatro nouvelles que componen Cicatrices están signadas por el juego: el billar de Angelito y Tomatis, los dados y los naipes de Sergio Escalante, la fabulación de los gorilas en el relato del juez homosexual López Garay, la caza de patos y esa otra caza mayor, el uxoricidio, en la voz del obrero Luis Fiore; cuatro testimonios que se van disolviendo hasta el absurdo, como anuncian los versos de Tomatis: "El rumor de un millón de mentes en continuo ronroneo, / en lenta disgregación" (52). "Locura" es, de hecho, la palabra pivote que escande el texto, repicando, una y otra vez, en los cuatro relatos como una pulsión. ${ }^{3}$

2 Al respecto, sería interesante plantear un análisis sistemático y detallado sobre el uso del doppelgänger en la narrativa de Saer: los dos personajes Salas en El limonero real (1974); Gina y López Garay en La ocasión (1988); Pichón y el Gato Garay, los hermanos mellizos en varios cuentos y novelas; el "dispositivo" que conforman Alfonso y Vilma en Lo imborrable (1992); Morvan y su alter ego Lautret (l'autre, "el otro") en La pesquisa (1994); Verde y Verdecito en Las nubes (1997), etc.

3 Vale aclarar que toda novela saeriana trabaja sobre una pulsión iterativa: una palabra o expresión pivote que se desprende del conjunto a fuerza de reiteración, oficiando de síntoma neurótico obsesivo. 
Pero Cicatrices es también, como Responso, la novela saeriana sobre el peronismo, sobre la fractura social que devino con la Revolución Libertadora y la liquidación del sentido en las vidas de unos personajes que colindan con el vacío, tras haber sido proscrito el movimiento popular más trascendental en la historia argentina: a la liquidación del sentido (político), sobreviene el azar encarnado en la ludopatía. En su irracionalidad y en su compulsión maniática, los juegos de azar son metáforas de la escritura: sin saber medir el clima, Angelito escribe la página del pronóstico del tiempo en el periódico La Región; el juez López Garay traduce por centésima vez El retrato de Dorian Gray, aun a sabiendas de la futilidad de semejante empresa - "únicamente a mí se me ocurre traducir algo que ya ha sido traducido un millón de veces" (33)-; Tomatis, con la indolencia epigramática entre melancólica e irónica que lo caracteriza, reconoce estar escribiendo "alguna cosa" sin saber de qué se trata pues "no llevo escritas más que trescientas páginas" (61).

Posiciones fracasadas que se afirman en una estética negativa: la información que no informa, el ensayo sin tesis, la traducción prescindible, la novela que naufraga sin rumbo; formas, todas ellas, reacias a la cristalización conceptual nítida o la institucionalización discursiva. Escribir sería, entonces, ceder ante una pulsión que no se explica ni se justifica, como si implícitamente informaran todos ellos el ideal estético de l'art pour l'art que hallamos en las palabras liminares de la celebérrima novela de Wilde que López Garay traduce:

The artist is the creator of beautifull things.

To reveal art and conceal the artist is art's aim [...]

We can forgive a man for making a useless thing as long as he does not admire it. The only excuse for making a useless thing is that one admires it intensely. All art is quite useless. (Wilde 5)

Deponer teorías previas, interpretaciones, preceptos, sesudas elaboraciones retóricas; $y$, en su lugar, limitarse a ver y narrar: ahí radica el común denominador de las cuatro historias que componen Cicatrices, rasgo muchas veces interpretado erróneamente por la crítica como un acatamiento a pie juntillas de los principios observacionales objetivistas y cinematográficos de la Nouveau Roman representada por Robbe-Grillet y Nathalie Sarraute; aunque en Saer la exacerbación descriptiva, su profunda convicción realista que lo impele a pararse frente a lo real para "narrar lo que ve", nunca viene despojada de su 
irónico reconocimiento de que ninguna experiencia sensible es susceptible de ser constatada: "El realismo que hay que suspender para saber de qué se trata la cosa incluye también a la literatura. Quizás en esto radique lo programático de una novela como Cicatrices: en el despojamiento de significados a los que cada uno de los cuatro narradores somete su pasión" (Arce, Un realismo 41).

Como el apostador, el escritor depende del azar, de la posibilidad remota de que aquello que su imaginación ha diseñado en su cabeza pueda o no plasmarse en un discurso literario, corriendo el riesgo de fracasar en su empresa: "El jugador debe apostar según se lo indica su imaginación. Apuesta a la posibilidad de que lo que ha imaginado que puede suceder, suceda" (125). Así, tanto en el terreno del juego como en el de la literatura,

La experiencia no se capitaliza. Cada destello de evidencia está separado de cada destello de evidencia por un abismo, y la relación que existe entre ellos permanece fuera del alcance de nuestro conocimiento. [...] Si la realidad coincide con nuestra imaginación, tenemos como premio un montón de excremento: dinero. (129)

Esos destellos -shocks, diría Benjamin- provocados por los incesantes estímulos sensoriales y perceptivos de la vida moderna no se dejan capitalizar en tanto "experiencia vivida", sino que, al igual que la frenética concatenación de influjos catódicos que la televisión y la computadora suministran, dejan al sujeto sumido en un estado de pasmo u obnubilación similar a aquel estado catatónico en que hallamos a un depresivo Tomatis en las páginas de Lo imborrable. Es, sin más, la hipermoderna contraposición entre conocimiento e información. Neutralizar el shock sería asignarle "a costa de la integridad de su contenido, un exacto puesto temporal en la conciencia" (Benjamin 9).

Pero tanto en la mesa de juego como en la línea sintagmática del significante literario, el recuerdo se resiste a devenir "experiencia vivida" manteniéndose, como sucede en la prosa de Proust, único e irrepetible, "aislado de la serie de los días" (31). Ahí se halla la raíz de la frustración de Tomatis: en su incapacidad de extraer del estímulo sensorial el sentido trascendental que Proust deriva de su famosa experiencia con la Madeleine. En sus reflexiones sobre el recuerdo voluntario o la mémoire volontaire en Proust, apunta Benjamin que "las informaciones que nos proporciona sobre el pasado no conservan nada de 
éste"; el pasado se halla, en palabras del propio Proust, "fuera de su poder y de su alcance, en cualquier objeto material (o en la sensación que tal objeto provoca en nosotros), que ignoremos cuál pueda ser" (124). Este impedimento de la evocación se vuelve particularmente drástico en nuestros tiempos de medios masivos y sobresaturación informativa, pues si las imágenes nos son provistas histéricamente sin interrupción, no queda resquicio alguno para que entre en juego la otra memoria, la involuntaria, aquella que define nuestra posibilidad de narrar una experiencia y, por lo tanto, de forjar una subjetividad. A esa reminiscencia involuntaria, desatada por asuntos tan triviales como el aroma de una Madeleine, se entrega Proust a lo largo de ocho profusos volúmenes; reminiscencia del objeto que, vista desde nuestros días, parece utópica dada la ya referida crisis de la experiencia y de la narración:

Otros, ellos, antes, podían. Mojaban, despacio, en la cocina, en el atardecer, en invierno, la galletita, sopando, y subían, después, la mano, de un solo movimiento, a la boca [...] Y yo ahora, me llevo a la boca, por segunda vez, la galletita en el té y no saco nada, pero nada, [...] ni experiencia, ni certidumbre, ni mensaje, ni signo, ni recuerdo: nada. (Saer, Cuentos 125-129)

El hecho de que la experiencia no pueda capitalizarse se refleja metafóricamente en el (ab)uso neurótico que Tomatis hace de la puntuación: cada destello o shock nace y muere simultáneamente sin llegar jamás a configurarse en tanto "experiencia vivida". Cada estímulo narrado por Tomatis en uno de los cuentos más vanguardistas de Saer se mantiene obsesivamente aislado del resto de los estímulos, así como cada revelación de un naipe en la mesa de juego, cada giro de la ruleta, cada golpe de dados constituye una entidad en sí misma, por completo aislada del resto. En "La mayor", las comas son los diques que impiden al narrador, justamente, narrar, concatenar estímulos aislados para hacer de ellos materia narrable; nunca como en dicho relato la sintaxis había sido tan violentamente fragmentada para metaforizar nuestra imposibilidad de capitalizar la información en experiencia de vida. Allí las comas son aquello que impide erigir un sentido sobre lo que se transmite, son el símbolo del balbuceo esencial al que el sujeto posmoderno ha quedado relegado en su catatonía hiperinformada.

La licuación de la categoría de autor acaba con la tiranía del sentido, pero también con el fin de toda experiencia entendida como trascendencia épica del mero acontecimiento, del vano devenir sin más. Quedan impresiones 
desperdigadas, retazos o jirones mnemotécnicos que no cristalizan en una sintagmática:

\begin{abstract}
A los recuerdos que vuelven por sí solos únicamente por costumbre o por resignación los llamamos nuestros, y si se nos diese por yuxtaponerlos igual que a una tira de diapositivas, la sucesión no solo sería inconexa desde un punto de vista temporal sino que no contaría, en ningún orden lógica, ninguna historia inteligible. (Saer, Lo imborrable 71)
\end{abstract}

Queda, en fin, el azar. Ya no contamos con una memoria dirigida que recomponga intencionalmente y asigne sentido, sino con el capricho evocador de la mémoire involontaire proustiana que, como sabemos, opera a fuerza de intermitencias, más allá de las voluntades individuales. La reiterada mención en "La mayor" del cuadro de Van Gogh ("Campo de trigo con cuervos") encarna precisamente, desde la pintura, la crisis profunda que Tomatis atraviesa: si el héroe saeriano no consigue recortar su figura del entorno y afianzarse en lo real; lo mismo aplica a los cuervos del cuadro. Nada en dicha pintura, de hecho, nos autoriza a la constatación: ¿los cuervos se aproximan o se alejan? ¿Es de día, como insinúa la luz solar reflejada sobre el trigo, o es de noche, como impone el cielo? Y así como las pinceladas minúsculas funden a los cuervos con el paisaje hasta disolverlos en el cielo, así también Tomatis es el sujeto hipermoderno que chapalea en la aguachirle de lo real disuelto y laxo. No solo carece del estatuto de autor que le garantizaría un territorio propio, que lo volvería dueño de una obra, figura de autoridad y referencia última de un sentido textual; sino que, como Van Gogh, se ha disuelto en el delirio esquizoide de las voces proliferantes que liquidaron las fronteras del yo. No es, ni fue, ni podrá ser como Pichón Garay, de esos bienaventurados "que están en la realidad / y no confunden / sus fronteras" (Saer, El arte de narrar 95); sino que él, como Escalante, carece de fronteras, es significante vacío cuyo aura se desborda hasta contaminarse con lo real, como los cuervos de Van Gogh o como el nimbo que desprenden los billetes de diez mil y que Escalante designa como "rebordes por donde se derrama el significado" (Saer, Cicatrices 160).

Desterrada toda posibilidad de relato, resta tan solo esperar un coup de dés. Si esos destellos aislados son los únicos que consiguen iluminar fugazmente la experiencia, se comprende que "la buena prosa" sea aquella que "trae consigo iluminaciones continuas" (ctd. en Prieto 82); prosa iridiscente que revele aquello que íntimamente el lector guardaba dentro suyo como experiencia vivida. 
Abolido todo sentido trascendental, el hombre moderno dispone solamente de revelaciones fugaces, de epifanías joyceanas, ${ }^{4}$ como las que en determinados pasajes de Glosa (1986) experimenta Ángel Leto, dejándolo tan confundido, como antes, una vez superadas:

La singularidad de este juego reside en que se trata de un juego de naturaleza compleja que me impide desde todo punto de vista una conducta racional, un juego en cuyo interior, un espacio limitado, debo moverme con los manotazos de ciego de mi imaginación y mi emoción y en el que la única certeza que puedo verificar por medio de mis sentidos, se presenta ante mis ojos con un relumbrón rápido, cuando ya no me sirve porque he debido apostar a ciegas, y enseguida desaparece. (Saer, Cicatrices 128)

Así transcurre la escritura para Sergio Escalante y para Carlos Tomatis, entre "los manotazos de ciego de mi imaginación y mi emoción" que se aferran con ansiedad a esas efímeras incandescencias que lo real condesciende, cada tanto, en mostrar.

\section{Melancolía i: tomatis y la troupe}

Años han pasado del bochornoso episodio con Adelina Flores y el autor le hará pagar caro a Tomatis su insolencia cuando reconozca humillado, en las páginas de Lo imborrable (1992), el efecto terapéutico que tuvo en su vida la composición de sonetos para lograr salir del pozo depresivo en que lo hallamos durante la última dictadura militar argentina. Lo que permanecerá invariable será, no obstante, la pulsión sexual vinculada al acto casi inconsciente de la escritura: "Durante la adolescencia, escribir sonetos había sido para mí una actividad casi tan frecuente como la masturbación: podía hacerlo varias veces por semana e incluso varias veces por día” (143).

4 Cuatro son, explica Abbate, los rasgos asociados a esta experiencia: "La realidad se presenta más ligera. El gozo es agudo y breve. Se altera la vivencia del tiempo. Supone un cierto desprendimiento del yo" (156). 
Si el producto de la masturbación va a parar al agua del inodoro, los sonetos de Tomatis van a parar al fuego, signo opuesto de equivalente destino en su derroche gratuito de libido que, lejos de sublimarse hacia la creación, se vuelve metáfora de la esterilidad en la melancólica figura del escritor sin escritura; imagen ya prefigurada, por otro lado, en La vuelta completa (1969), cuando Tomatis devuelve una clásica respuesta de héroe saeriano ante César Rey quien, menos por interés que por aburrimiento, inquiere sobre su novela en marcha: "Bien -dijo Tomatis. No escribo nunca" (308). Confesará incluso, ya nuevamente en Lo imborrable, dominar con soltura la forma del soneto al punto de "improvisarlos en medio de una conversación lo cual significaba para mí que estaba desprovisto de toda legitimidad poética" (143).

Más allá de la solapada alusión a Lope de Vega, a quien se le atribuye la composición espontánea de su famoso "Un soneto me manda hacer Violante" como triunfal respuesta a un desafío público, interesa más bien detenerse en la actitud estética arcaizante que Tomatis, hombre reaccionario al fin y al cabo, renueva en su anacrónica noción de "legitimidad poética". Así entendida, la práctica poética queda confinada al reino exclusivo de la escritura, de la elaboración artesanal y el trabajo riguroso sobre la forma compleja. Y no, como suele insistirse en nuestros días de extremo relajamiento textual, a otras prácticas discursivas signadas por la oralidad, la creación espontánea y, sobre todo, la simpleza, la ausencia de esfuerzo en el artista o de complejidad en la forma.

No hace falta indagar demasiado en la prosa ensayística de Saer para percibir las similitudes en su concepción del fenómeno estético, en las antípodas del credo relativista y en la banalización del arte que las huestes del posmodernismo promovieron en los últimos cuarenta años. Como Tomatis, Saer jamás habría condescendido en equiparar conversación con poesía, como suelen hacerlo ciertos teóricos posmodernistas para quienes toda producción lingüística se nivela en la difusa categoría de "prácticas discursivas". Para Tomatis, como para Saer, literatura implica coto cerrado, terreno delimitado:

Las poéticas poeticistas, entonces, como la de Saer, son poéticas 'cerradas': para ellas, no pertenecen a la literatura sino aquellos textos marcados por el sello de la poeticidad. en virtud de la elisión, la condensación, el ritmo y su capacidad para la polisemia, la poesía proporciona una imagen de la vida humana que es mucho más densa y compleja, y encarna esa necesaria 'indeterminación de sentido' que Saer le exige a la literatura. (Abbate 152) 
Se suceden así, tanto en Tomatis como en el resto de la troupe, declaraciones que manifiestan posiciones contrahegemónicas sobre la solemnidad en la literatura, sobre los usos sociales normalizados de su práctica y circulación que, vistos a la distancia, provocan náuseas en escritores frustrados que reniegan de su pasado literario ("esos cuentos estúpidos, moravianos, en un diario de provincias”) como César Rey en La vuelta completa (1966):

No solo no he escrito, sino que ni siquiera lo he intentado. Más todavía: cada vez que pienso en la literatura, empiezo a echar espuma por la boca [...] Sin embargo aquella mañana yo estaba metido hasta el cuello en la atmósfera de la literatura. A nuestra edad ya no es posible: hace falta una buena dosis de ingenuidad, o de inocencia, o no sé qué. (22-39)

La cohesión de la troupe saeriana se construye sobre una filiación negativa del mundo y de la literatura cristalizada en conversaciones chispeantes y plagadas de sobreentendidos que las nuevas generaciones (Soldi, Gabriela Barco, Nula) no alcanzan a decodificar. Unidos, menos por el amor que por el espanto, la troupe se compone de jóvenes intelectuales santafesinos que chapalean en el agua chirle negra de la melancolía con ironía desesperada (Premat): Horacio Barco cierra "Algo se aproxima" y La vuelta completa estatuyendo el sinsentido de la vida; César Rey se arroja a las vías del tren (o tropieza, según ciertas lenguas, reavivando la discusión de Glosa sobre los caballos y sus tropiezos); Pancho Expósito, otro asiduo al neuropsiquiátrico, se encarga de fustigar a Lugones desde su cátedra escolar de literatura argentina; Rosemberg y Escalante, personajes dostoievskianos, se regodean en el masoquismo de sus pulsiones autodestructivas; y Carlos Tomatis, por último, se diría el heredero directo de Washington Noriega, de su impronta epigramática y paradojal:

$-\dot{i}$ Adelantaste mucho esta semana?

-Nada -dijo él [...] Estoy hasta la coronilla de literatura.

-Es saludable -dijo Barco [...].

-Sí -repiti ó él-. Es saludable.

-Viejo -dijo Barco-: si hacés tantos problemas para escribir una miserable novela quiere decir que la literatura no te interesa para nada-

$-\dot{i}$ Acaso me estoy quejando? (Saer, Cuentos 503)

-¿Qué se experimenta siendo escritor? -dijo.

-Falta de plata, corazón -dijo Tomatis. (Saer, La vuelta completa 125) 
-Desgraciadamente, todo el mundo tiene sentimientos -dijo-. Por lo tanto todo el mundo hace literatura.

-Conozco a un tipo que no tiene sentimientos y sin embargo hace literatura -dije yo.

-Ha de ser un buen escritor -dijo Tomatis. (Saer, Cicatrices 79)

Saturados, hastiados, "hasta la coronilla", "echando espuma por la boca" frente a la literatura y, sin embargo, monotemáticos, empedernidos lectores incapaces de hablar de otra cosa, dependientes natos de los esquemas literarios que emplean para filtrar la experiencia humana y para "leer" la realidad, obsesivos como Angelito en Cicatrices (1969) que devora cinco novelas en tres días, o como el Matemático en Glosa (1986), que sale corriendo para fatigar la obra de un autor desconocido que Tomatis mencionó indolentemente. La troupe reproduce, entonces, el tono hostil que apreciamos en los ensayos de Saer de los años 60 y 70, signados por la contradicción lacerante del hombre de letras que abomina de la idea de literatura que su sociedad trafica en su doxa.

Pero Tomatis es también, como el tape Waldo de La ocasión (1988), el escritor agorero, el visionario, el lector sagaz, aquel que desmantela la lectura psicoanalítica de Pichón para dar con el verdadero culpable en La pesquisa, trocando una justificación edípica de manual -Morvan- por una basada (cuándo no) en la pulsión irracional -Lautret-; o aquel que cifra el sentido último de la novela en el epígrafe de Glosa: "En uno que se moría / Mi propia no muerte no vi, / Pero en fiebre y geometría / Se me fue pasando el día / Y ahora me velan a mí" (9), al ponerlo en relación con el cuento "Amigos", donde Ángel Leto no ve su propia muerte en aquel hombre que la guerrilla le encomienda asesinar, como tampoco ve su propio suicidio con una pastilla de cianuro en el balazo con el cual su padre se quita la vida. Si Leto remite a la fiebre; el matemático, a la geometría.

Fiebre y geometría son también los estados bipolares que atraviesa el melancólico, la contraposición irreconciliable de luz y sombra que Van Gogh nos brinda en su "Campo de trigo con cuervos". Fiebre es la transgresión de Sor Juana Inés de la Cruz en su "Primero sueño", delirándose en tanto Faetón o Ícaro en vuelo ascendente; geometría es el amargo reconocimiento del universo en tanto "espantosa máquina inmensa" de "terrible incomportable peso" (De la Cruz, 1994, 88) en el declive de su aventura epistemológica. Al querer ingresar 
en una dimensión metafísica que excede las capacidades humanas, el alma reconoce sus limitaciones y se sumerge en un estado melancólico, como aquel famoso ángel que Durero retrata en pose compungida mientras sostiene un compás y una regla sobre su regazo, pues la melancolía, siguiendo a Premat en su análisis de dicho grabado, "yuxtapone dos elementos contradictorios provenientes de fuentes distintas: un alma sensible, ensimismada en su subjetividad dolorosa, y un espíritu lógico, dotado de los instrumentos necesarios para aprehender y reproducir el universo" (361). Basta evocar "Duelo y melancolía" para completar el retrato de Carlos Tomatis:

La melancolía se singulariza en lo anímico por una desazón profundamente dolida, una cancelación del interés por el mundo exterior, la pérdida de la capacidad de amar, la inhibición de toda productividad y una rebaja en el sentimiento de sí que se exterioriza en autorreproches y autodenigraciones y se extrema hasta una delirante expectativa de castigo. (Freud 253)

La inhibición de toda productividad resulta el más claro de los rasgos melancólicos de Tomatis, pues jamás puede redondear la novela que tanto fatiga a lo largo de décadas, haciendo suya la máxima de Washington en Glosa ("no viá dejar más que fragmentos"). En lo que respecta a la cancelación del interés por el mundo exterior, la sentencia de Angelito resulta elocuente: "Pienso que no le interesa nada, absolutamente nada. Y de ese modo, puede hacer cualquier cosa" (46). La pérdida de la capacidad de amar viene acompañada, en su caso, del complejo de castración que exhibe en las páginas de Lo imborrable (1992) tras la muerte de su madre, cuando percibe su propia genitalidad al borde de la desaparición. Los reproches y las autodenigraciones, por último, también están a la orden del día: "Nos las tiramos de santos; ya lo sé. Son macanas; somos como todos: bosta pura. Cacareamos humanismo y literatura. Cháchara inmoral. Todo, todo. Puras macanas" (Saer, La vuelta completa, 176). De hecho, en Tomatis la pulsión de muerte subordina sin más a la pulsión de amor. En la única novela que lo tiene por narrador protagonista, la estructura iterativa que escande el texto es la variación de un giro idiomático que incita inconscientemente, apunta Premat (129), a la punición sádica basada en la castración genital: "que me la corten en rebanadas" (Saer, Lo imborrable 52); "que me cuelguen del pobre aditamento ya casi inexistente y me dejen colgado el resto de mis días" (75); "que me maten una y mil veces" (124). 
Una figura melancólica como la de Tomatis exhibe su biblioteca, detenta con arrogancia los instrumentos de su conocimiento, refuta teorías encumbradas y desafía la autoridad en cualquiera de sus variantes culturales (en Cicatrices, por ejemplo, juzga a Otello una obra menor por parecerle melodramático aquello del celoso homicida). En su última intervención, de hecho, como apuntan Sarlo y Ferres González, se niega a tolerar que una red de hipermercados llamada Warden ("guardia", "vigilante", en inglés) sea confundida con el verbo nodal del idealismo filosófico alemán (werden, "devenir"), cerrando con ello el ciclo abierto en "La mayor" y en Cicatrices: en nuestras sociedades hipermodernas signadas por el culto a un presente eufórico, nada "deviene" (werden); otros, ellos, antes, podían; la última observación de Tomatis, por el contrario, denuncia con sorna resignada la lógica del hipermercado que rige nuestras vidas: producción en masa, despersonalización e hipervigilancia histérica ("Warden”):

Se consolidan sociedades reorganizadas por la lógica e incluso por la temporalidad de la moda, vale decir por el presente, que sustituye la acción colectiva por la felicidad privada, la tradición por el movimiento, las esperanzas del futuro por el éxtasis de la novedad perpetua. [...] Consumir con impaciencia, viajar, divertirse, no renunciar a nada: tras las políticas del porvenir radiante ha venido el consumo como promesa de un presente eufórico. (Lipovetsky et al. 64)

La fiebre de Carlos Tomatis bosqueja su costado maníaco: promiscuo, lascivo, errabundo e inquieto, cárnico, lúbrico, asiduo a los cabarets y propenso al vino, las picadas, los asados y los cigarros Romeo \& Julieta. Su geometría, en cambio, delinea su costado depresivo: su abstinencia programática durante la dictadura, ${ }^{5}$ las sopas acuosas, el confinamiento voluntario y su adicción a los antidepresivos y la televisión. Ese movimiento pendular pareciera ser

5 Una interesante lectura de Luppi sobre la abstinencia de Tomatis en Lo imborrable (1992): "Funciona como alegoría de la negatividad a ceder la autonomía intelectual en la reorganización cultural posterior a la dictadura; la sed que trama la voz íntima, su dilema entre beber o mantenerse sobrio, pauta el recorrido del personaje entre el aislamiento y la reintegración a una sociedad quebrada por la paranoia y la planificación mercantil" (2). 
constitutivo de toda actividad creativa. No en vano revela Saer en una entrevista sentir "una breve euforia a la que sigue cierta melancolía" (ctd. en Prieto 149) cada vez que da por terminado un libro.

\section{Eppur si muove}

Y, no obstante, tras tantos escritores estériles que, afincados en su Zona, no dan con su palabra, se oye otra voz indeterminada y desapercibida que va narrando: la voz del autor. Lejos, entonces, de erigirse Tomatis en portavoz de Saer, se diría su inversión especular.

Una de las últimas escenas de la última novela saeriana nos brindará una imagen fastuosa de Tomatis para la posteridad, en todo su esplendor epicúreo, regodeado entre los múltiples placeres de la bacanal dominguera que Gutiérrez ha planeado a su regreso. Hay algo cervantino en su epifanía, pues la escena evoca vagamente los célebres discursos que el Quijote, extasiado entre amigos, se siente inspirado a declamar:

De golpe, en un fogonazo de clarividencia, acaba de comprender por qué están todos juntos, reunidos alrededor de esa mesa, distendidos y contentos: porque ninguno entre los presentes, piensa Tomatis, cree que el mundo le pertenece. Todos saben que están a un costado de la muchedumbre humana que tiene la ilusión de saber hacia dónde se dirige y ese desfasaje no los mortifica; al contrario, parece más bien satisfacerlos. [...] Tienen razón de ser tal como son, exteriores a la bandada, volando solitarios en el cielo vacío, con el propio delirio como brújula y una ruta incierta, sin plan anticipado, como derrotero. Porque si es verdad que en la muchedumbre gris y somnolienta desfilan durante un tiempo, más o menos largo, muchos de los que algún día van a despertarla, no es menos cierto que los que del nacimiento a la muerte han vivido al margen de ella, a veces incluso sin saberlo, son los que con más justicia son capaces de juzgarla. Son pasto de su delirio, es cierto, pero también, color del mundo. (Saer, La grande 408-409)

Rodeado de su modesto happy few, Tomatis se despide. Y lo hace revisando una a una todas las obsesiones saerianas en torno de la escritura: 
los shocks epifánicos de Escalante y Leto ("fogonazo de clarividencia"), la postulación de un beatus ille encarnado en Washington Noriega-Macedonio y Juan L. - ("a un costado de la muchedumbre humana", "volando solitarios en el cielo vacío"), la reivindicación de una escritura a lo viejo grumete: instancia pulsional e incierta ("con el propio delirio como brújula"), sin prejuicios ni teorizaciones previas ("sin plan anticipado, como derrotero"). Los de acá "son los que con más justicia son capaces de juzgar" a los de allá, "muchedumbre gris y somnolienta", lectores de Walter Bueno (Lo imborrable), Mario Brando (La grande), el tape Waldo (La ocasión), verdaderos escritores orgánicos. ${ }^{6}$

Los de acá, por el contrario, participan de una filiación tan íntima como exclusiva sustentada en la desconfianza, la sorna epigramática, la solidaridad trasnochada, la charla erudita, la negación del mundo y del arte institucionalizado. En el universo Tomatis entroncado con la caravana del doctor Real y sus locos de Las nubes (1997), Los de acá "son pasto de su delirio, es cierto, pero también, color del mundo".

\section{Referencias}

Abbate, Florencia. El espesor del presente. Córdoba: EDUVIM, 2014.

Arce, Rafael. "Un realismo de lo real: la imaginación material en la obra de Juan José Saer". Anclajes, 13 (2013): 9-25.

Arce, Rafael. "La pasión de lo real”. Realismos, cuestiones críticas, 29 (2013).

Arce, Rafael. "La imagen novelesca”. Revista Hispánica Moderna, 66 (2013): 109-120.

Benjamin, Walter. “Sobre algunos temas en Baudelaire”. Obras I, vol. II. Madrid: Abada, 2012.

Bermúdez Martínez, María. La incertidumbre de lo real: bases de la narrativa de Juan José Saer. Oviedo: Departamento Publicaciones de la Universidad de Oviedo, 2015.

Chuck, Aída Nadi Gambetta. "Juan José Saer: la magnitud de La grande (2005)". Texturas, 1.7 (2015): 47-52.

Dalmaroni, Miguel. "El grafismo visible de la voz de lo real. La lección del poema en Juan José Saer”. Estudios, 18.36 (2011): 81-101.

De la Cruz, Sor Juana Inés. "Primero sueño". Obra selecta II. Caracas: Biblioteca Ayacucho, 1994.

6 Como se detalla en un trabajo de reciente publicación (Longoni) 
Di Benedetto, Antonio. Trilogía de la espera: Zama. El silenciero. Los suicidas. Buenos Aires: Adriana Hidalgo editora, 2016.

Freud, Sigmund. "Duelo y melancolía”. Obras completas, vol. 14. 1917: 235-255. Buenos Aires: Amorrortu, 1976.

Gramuglio, María Teresa. Juan José Saer por Juan José Saer. Buenos Aires: Celtia, 1986.

Gramuglio, María Teresa. "El lugar de Saer”. Revista Crítica Cultural, 5.2 (1984): 325 347.

Hutnik, Erik. "La figura del escritor. Dos generaciones en Argentina”. Revista Crítica Cultural 7.1 (2012): 53-65.

Lipovetsky, Gilles y Sébastien Charles. Los tiempos hipermodernos. Barcelona: Anagrama, 2012.

Longoni, Bruno. “Escritores orgánicos en la novelística de Juan José Saer”. Cartaphilus 15 (2018): 35-57.

Luppi, Juan Pablo. "La sed de una amarga fruta argentina. Desgarros públicos y privados de la última dictadura en Lo imborrable de Juan José Saer”. Hologramática, 9.5 (2008): 3-27.

Maccioni, Laura. "Enigma, política y lenguaje en Cicatrices y La Mayor: Juan José Saer en los setenta (y un diálogo con Rodolfo Walsh)". Chasqui, 44.1 (2015): 48-64.

Monteleone, Jorge. "Lo póstumo: Juan José Saer y La grande”. Ínsula. Revista de letras $y$ ciencias humanas, 711 (2006): 14-17.

Panesi, Jorge. "Cicatrices de Juan José Saer: el peligroso juego de la literatura”. Pie de página, 2 (1983): 28-29.

Piglia, Ricardo. Las tres vanguardias: Saer, Puig, Walsh. Buenos Aires: Eterna Cadencia, 2016.

Premat, Julio. La dicha de Saturno: Escritura y melancolía en la obra de Juan José Saer. Rosario: Beatriz Viterbo Editora, 2002.

Premat, Julio. "Saer: un escritor del lugar". Héroes sin atributos: Figuras de autor en la literatura argentina. Buenos Aires: FCE, 2009.

Premat, Julio. “La grande: volver a empezar”. Cuadernos LIRICO, 6 (2011): 173-182.

Saer, Juan José. Cuentos completos. Buenos Aires: Seix Barral, 2012.

Saer, Juan José. El arte de narrar. Madrid: Visor libros, 2010.

Saer, Juan José. La vuelta completa. Buenos Aires: Seix Barral, 2014.

Saer, Juan José. Cicatrices. Buenos Aires: Seix Barral, 2015.

Saer, Juan José. Nadie nada nunca. Barcelona: Rayo Verde, 2014.

Saer, Juan José. El entenado. Barcelona: Rayo Verde, 2013.

Saer, Juan José. Glosa. Barcelona: Rayo Verde, 2015.

Saer, Juan José. La ocasión. Buenos Aires: Booket, 2013.

Saer, Juan José. El río sin orillas. Buenos Aires: Seix Barral, 2015.

Saer, Juan José. Lo imborrable. Buenos Aires: Seix Barral, 2013.

Saer, Juan José. La pesquisa. Barcelona: Rayo Verde, 2012.

Saer, Juan José. El concepto de ficción. Buenos Aires: Seix Barral, 2014.

Saer, Juan José. Las nubes. Buenos Aires: Seix Barral, 2004. 
Saer, Juan José. La narración-objeto. Buenos Aires: Seix Barral, 2014.

Saer, Juan José. La grande. Buenos Aires: Seix Barral, 2012.

Saer, Juan José. Ensayos. Borradores Inéditos 4. Buenos Aires: Seix Barral, 2015.

Sarlo, Beatriz. Zona Saer. Santiago de Chile: Ediciones Universidad Diego Portales, 2016.

Torres, Andrea. "Narración y efecto de temporalidad en La grande de Juan José Saer". Scritture plurali e viaggi temporali, 55 (2013).

Wilde, Oscar. The picture of Dorian Gray. Londres: Penguin Classics Edition, 2003. 